\title{
ENHANCING STUDENT LEARNING OF ERP CONFIGURATION THROUGH A QUICKBOOKS TUTORIAL
}

\author{
Kamal Hingorani, Alabama State University, khingorani@alasu.edu \\ Brooke Beasley, Alabama State University, bbeasley@alasu.edu \\ Jorja Bradford, Alabama State University,jbradford@alasu.edu
}

\begin{abstract}
As most large and medium-sized businesses in the US standardize on Enterprise Resource Planning software, business and engineering schools have incorporated courses that focus on ERP in their curriculum to better prepare students for the real-world. The SAP University Alliance has helped in this effort through providing free software, curriculum and faculty training to incorporate effective ERP courses in both the undergraduate and graduate programs. The complexity of the SAP software and the desire for introducing courses on configuration of SAP has challenging implications for faculty as some students treat the course as a mouse-clicking exercise while others focus on being the first to finish. The understanding and grasping of the underlying concepts becomes a casualty in such courses. This paper presents the use of QuickBooks for Accounting for mirroring the business on a software that is relatively more intuitive and easy to use. The students ended with a better understanding of the underlying concepts involved in configuring a business on SAP.
\end{abstract}

Keywords: Information Technology (IT), SAP, QuickBooks, ERP, Student Learning.

\section{INTRODUCTION}

As most large and medium-sized businesses in the US standardize on Enterprise Resource Planning software, business and engineering schools have incorporated courses that focus on ERP in their curriculum to better prepare students for the real-world [1]. The SAP University Alliance (UA) has enabled a large number of universities across the world to introduce SAP curriculum in business and engineering programs. Besides providing hosted access to the entire suite of SAP software, the UA has also developed curriculum that can be adopted in semester long courses. They also provided free training to faculty members for effective implementation of these courses. Our University has been a member of the SAP University Alliance since 2000 and has incorporated ERP configuration in the undergraduate business curriculum. We presently use the SAP ERP configuration using the Global Bike Inc. case as a major component of a 3 -semester credit hours $(\mathrm{SCH})$ junior-level course.

Although the SAP R/3 configuration supports experiential and student-centered learning, teaching ERP configuration to undergraduate students has always been a challenge. Many students find the whole process of ERP configuration very tedious and some students follow the instructions as a typing or a mouse-clicking exercise. Even some of the high-performing students strive on being the first to finish although there are no points attached for such an achievement. This is despite the faculty telling them to focus on the underlying concepts while doing the handson exercises.

This paper describes the use of QuickBooks Accountant 2013 for configuring the same fictitious company (Global Bike Inc. that was used for SAP configuration) using a tutorial that was developed in-house. The reinforcement of concepts through hands-on exercises on a more intuitive and easy-to-use interface helped the students better grasp the concepts and also appreciate the complexity of configuring the same company on SAP.

\section{QUICKBOOKS ACCOUNTANT}

QuickBooks is an accounting software package that is directed toward small and medium-sized businesses. It has a market share of around 90 percent in North America, making it one of the most powerful and long-lasting nearmonopolies in the world of business software [2]. The software comes in many flavors. The QuickBooks Accountant is now in its 2015 version; our university still uses the 2013 version which has most of the required functionalities. 
Although QuickBooks is described as an accounting software, it uses the same nomenclatures that are used in a high-end ERP software. The nomenclature used by QuickBooks for business processes are very similar to the ones that are used in SAP R/3 which allows the new learner to reinforce his understanding of business processes and the underlying terminology if the same company is configured in both the software platforms.

The QuickBooks Accountant has a Windows-based menu-driven interface that is very easy to comprehend and use. The interface has a left navigation menu to complement the top menu. The main screen of the software is shown in Figure 1.

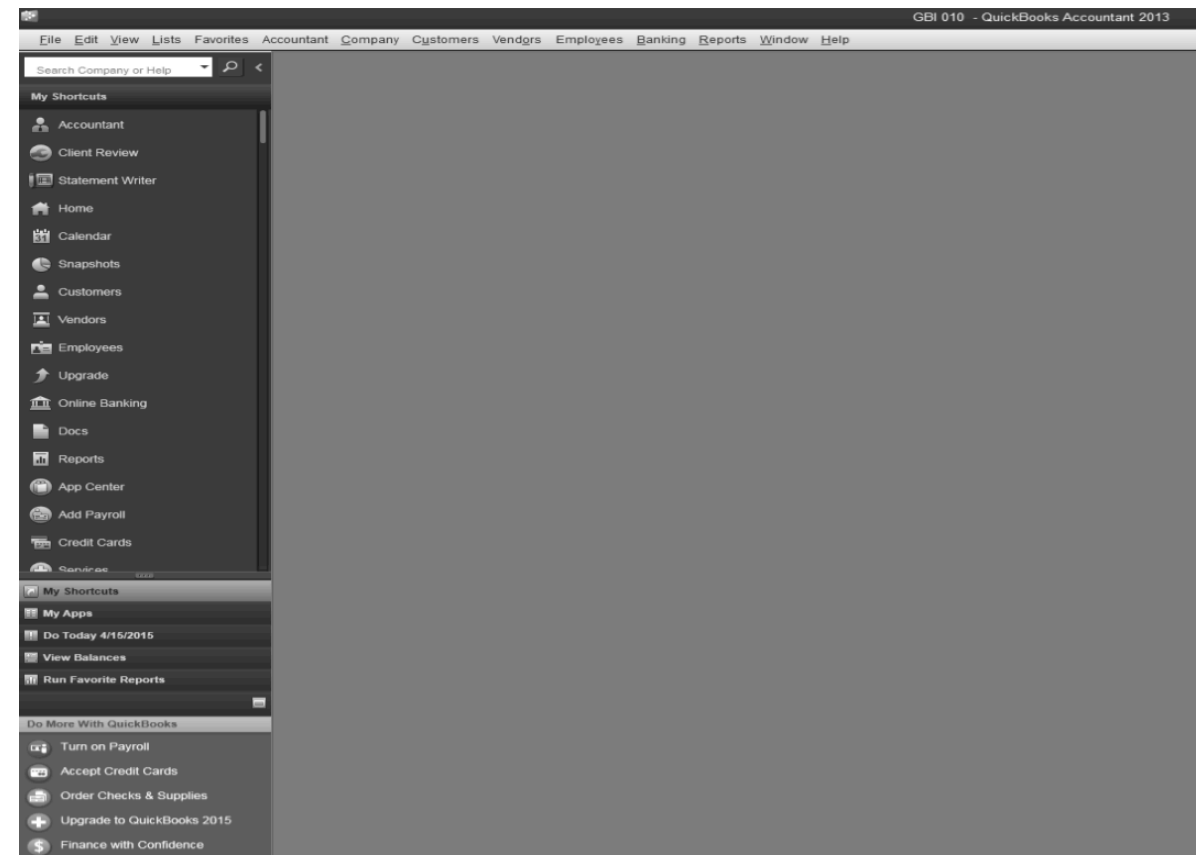

Figure 1. QuickBooks’ Main Screen

The key components of the interface are detailed below:

- Menu Bar- the Menu Bar is the top bar across the screen which consists of the following tabs: File, Edit, View, Lists, Favorites, Accountant, Company, Customers, Vendors, Employees, Banking, Reports, Window, and Help. The Menu Bar is frequently used in completing transactions.

- Navigation Bar- the Navigation Bar is the long bar on the left side of the screen. It is used for quick links to key actions that will take place throughout the process of entering data.

\section{GLOBAL BIKES CONFIGURATION AND PROCESS EXECUTION ON SAP}

The SAP UA SAP R/3 GBI case configuration manual is a copy-righted product of the SAP University Alliance [4, 7, 8]. The manual includes six phases: Financial Accounting, Procurement, Fulfillment, Production, Material Planning, and Warehouse Management. Our study targeted only the first three phases of the configuration. The Financial Accounting Phase has four parts with 44 pages of documentation involving a total of 36 hands-on exercises. The Procurement Phase has four parts with 42 pages of documentation involving 26 hands-on exercises. The Fulfillment Phase has four parts with 35 pages of documentation involving 24 hands-on exercises. The configuration and process execution are done in each of the phases as detailed in Table 1 below: 
Table 1. GBI Configuration on SAP

\begin{tabular}{|c|c|c|}
\hline Phases & $\begin{array}{c}\text { Process Execution } \\
\text { (Number and Process Description) }\end{array}$ & Configuration Exercises \\
\hline $\begin{array}{l}\text { Phase I- Financial } \\
\text { Accounting ( } 44 \text { pages } \\
\text { and } 36 \text { exercises })\end{array}$ & $\begin{array}{l}\text { Four exercises: Review Accounts, Display Balances } \\
\text { I, Enter General Ledger Account Postings, Display } \\
\text { Balances II }\end{array}$ & 32 \\
\hline $\begin{array}{l}\text { Phase II- Procurement } \\
(42 \text { pages and } 26 \\
\text { exercises) }\end{array}$ & $\begin{array}{l}\text { Five exercises: Create Purchase Requisition, Create } \\
\text { Purchase Order, Create Goods Receipt, Receive } \\
\text { Invoice, Pay Vendor }\end{array}$ & 21 \\
\hline $\begin{array}{l}\text { Phase III- Fulfillment } \\
\text { (35 pages and } 24 \\
\text { exercises) }\end{array}$ & $\begin{array}{l}\text { Six exercises: Create Sales Quotation, Create Sales } \\
\text { Order, Create Outbound Delivery, Ship Materials, } \\
\text { Create Invoice, Receive Payment }\end{array}$ & 18 \\
\hline
\end{tabular}

\section{GLOBAL BIKES CONFIGURATION AND PROCESS EXECUTION ON QUICKBOOKS}

The Global Bike configuration and process execution manual on QuickBooks that was developed for this study has one phase divided into four parts. The entire manual has just 27 pages with 4 exercises on configuration, 4 exercises on General Ledger Entries, 6 exercises on the Purchase cycle, and 6 exercises on Fulfillment cycle. The details are summarized in Table 2 below.

Table 2. GBI Configuration on QuickBooks

\begin{tabular}{|l|l|l|}
\hline \multicolumn{1}{|c|}{ Parts } & \multicolumn{1}{|c|}{ Configuration Activities } & \multicolumn{1}{c|}{ Process Execution } \\
\hline $\begin{array}{l}\text { Part I: Configure a } \\
\text { New Company }\end{array}$ & $\begin{array}{l}\text { Create a New Company, Set Up } \\
\text { Bank Account, Add Products } \\
\text { (Trading Goods), Add Vendors and } \\
\text { Customers }\end{array}$ & \\
\hline $\begin{array}{l}\text { Part II- Complete } \\
\text { General Ledger } \\
\text { Entries }\end{array}$ & - & $\begin{array}{l}\text { Four exercises: Add Capital Stock, } \\
\text { Buy Office Supplies, Print Balance } \\
\text { Sheet Reports }\end{array}$ \\
\hline $\begin{array}{l}\text { Part III- } \\
\text { Procurement } \\
\text { (Purchase Cycle) }\end{array}$ & - & $\begin{array}{l}\text { Six exercises: Create Purchase } \\
\text { Order, Receive Items, Print } \\
\text { Inventory Report, Enter Invoice } \\
\text { (Bill), Pay Vendor, Print Balance } \\
\text { Sheet Reports }\end{array}$ \\
\hline $\begin{array}{l}\text { Part IV- Fulfillment } \\
\text { Sales Cycle) }\end{array}$ & - & $\begin{array}{l}\text { Seven exercises: Create Sales } \\
\text { Order, Fulfill Sales Order, Create } \\
\text { Invoice, Print Inventory Valuation } \\
\text { report, Receive Payment, Print } \\
\text { Income Statement Report. }\end{array}$ \\
\hline
\end{tabular}

The manual included the user printing a series of pre-formatted reports on QuickBooks to better understand the business processes and the underlying accounting system.

\section{Configuring the GBI Inc. on QuickBooks}

QuickBooks makes setting up a company very seamless with their easy to follow "Easy Step Interview". The data that a user has to supply are:
a. Name and address of the company
b. The industry type (manufacturing in our case to match the GBI case study )
c. Selecting Tracking Inventory in QuickBooks as True.

Additional configuration of the business such as adding Bank Accounts, Vendors, Customers, and Inventory items are all done through a start-up screen as shown in Figure 2. 


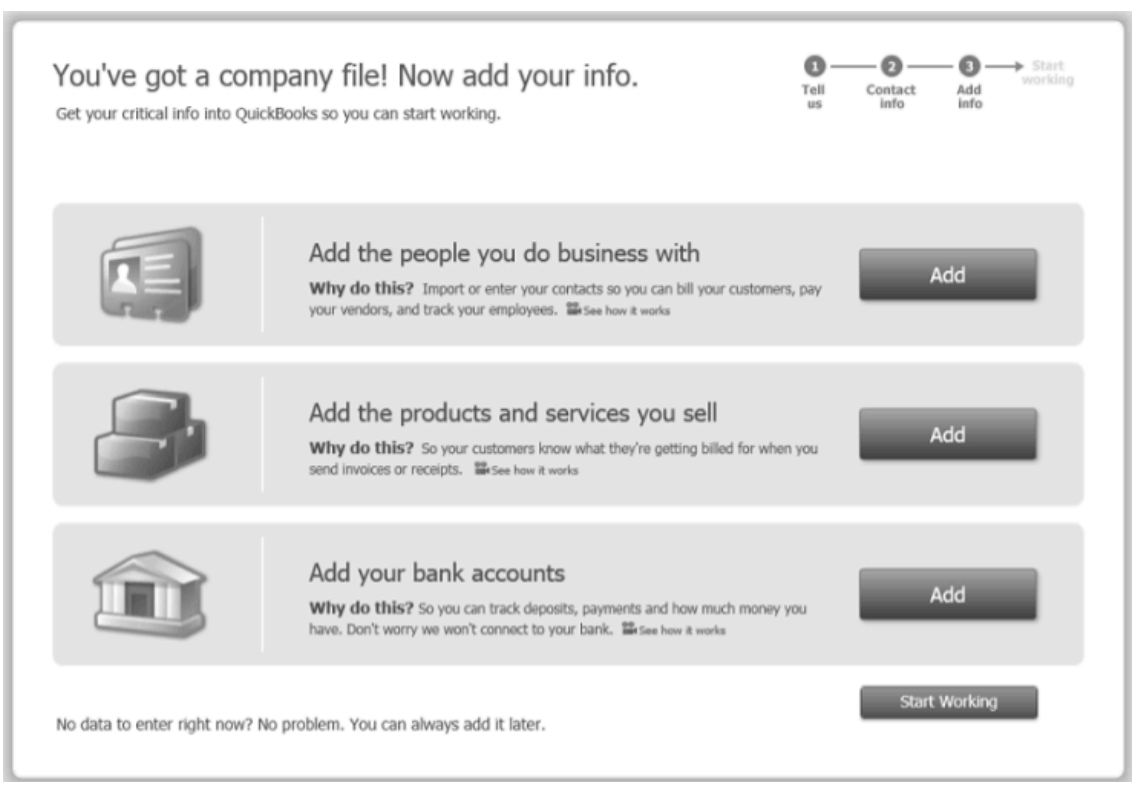

Figure 2. Start-up Screen for Adding Customers, Vendors, Products, and Bank Accounts

The configuration involved in duplicating the GBI case was setting up one bank account, one customer, one vendor, and 10 trading goods inventory items. Since the program is windows-based, the information from the manual can be copied and pasted in QuickBooks. The configuration process is done upfront before starting any of the process activities. The entire configuration process can be finished in under 20 minutes.

\section{Process Activities for General Ledger Entries}

The interface for process execution in QuickBooks is described next. The process activity of adding capital stock is done on the following screen.

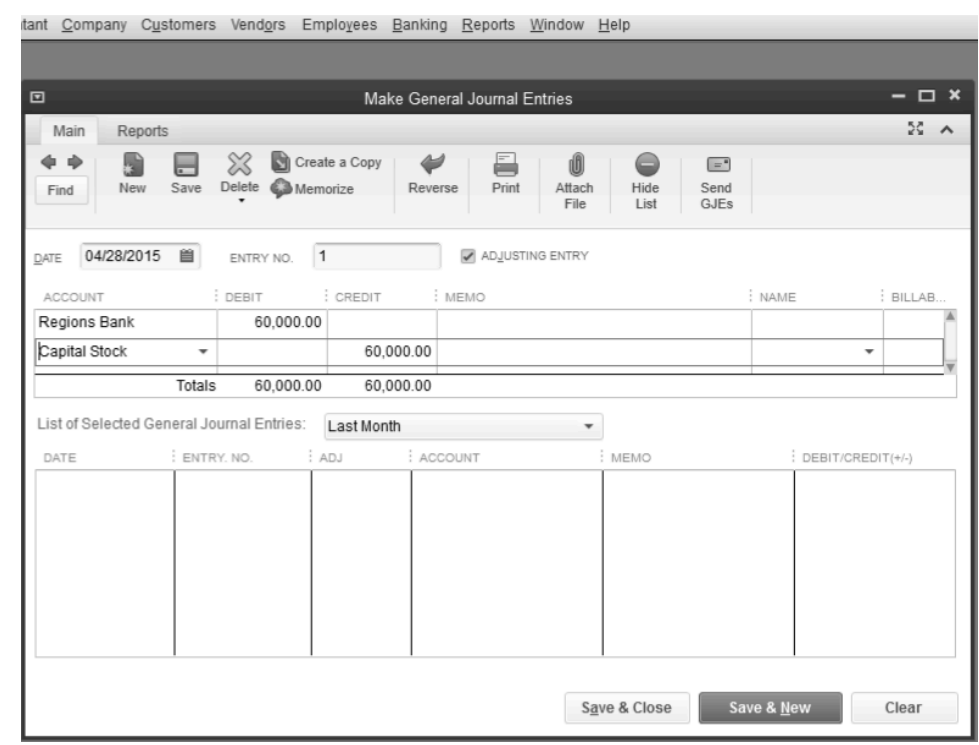

Figure 3. Add Capital Stock

The student gets a better grasp of the underlying chart of accounts (selection of accounts is through drop down boxes). QuickBooks uses double-entry accounting — the worldwide standard for business accounting. In double- 
entry accounting, every transaction records in at least two accounts - in one as a debit and in the other as a credit. This concept covered in the introductory accounting class is reinforced through this exercise using a simple interface. In the general ledger entry exercise involving buying office supplies shown in Figure-4, the student learns that a debit to office supplies is followed by a credit to a bank account. This concept can sometimes be difficult for a non-accounting major to comprehend and remember.

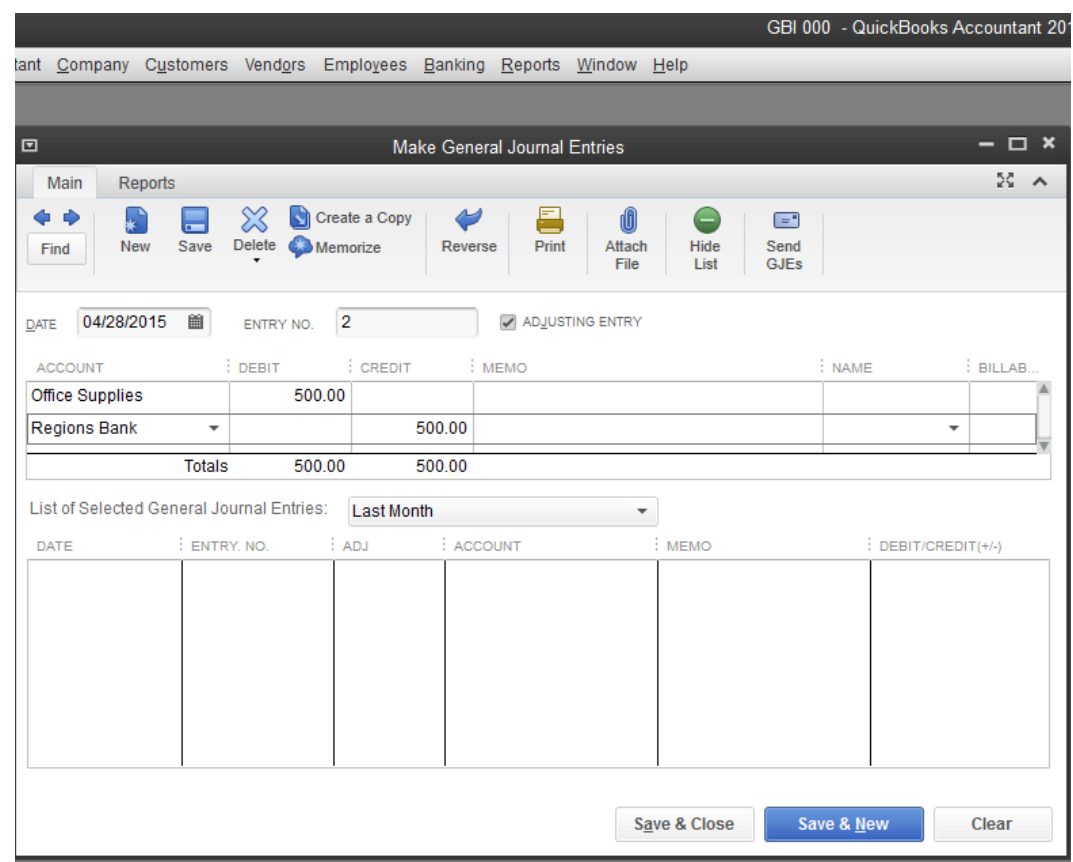

Figure 4. Buy Office Supplies

The student is required to print a balance sheet after completing the general ledger entries. The balance sheet shows how a small business can handle office supply expenses. The IRS allows a small business to deduct $100 \%$ of office supplies as expenses and the balance sheet reports this expense as Net Income with a negative sign as shown below.

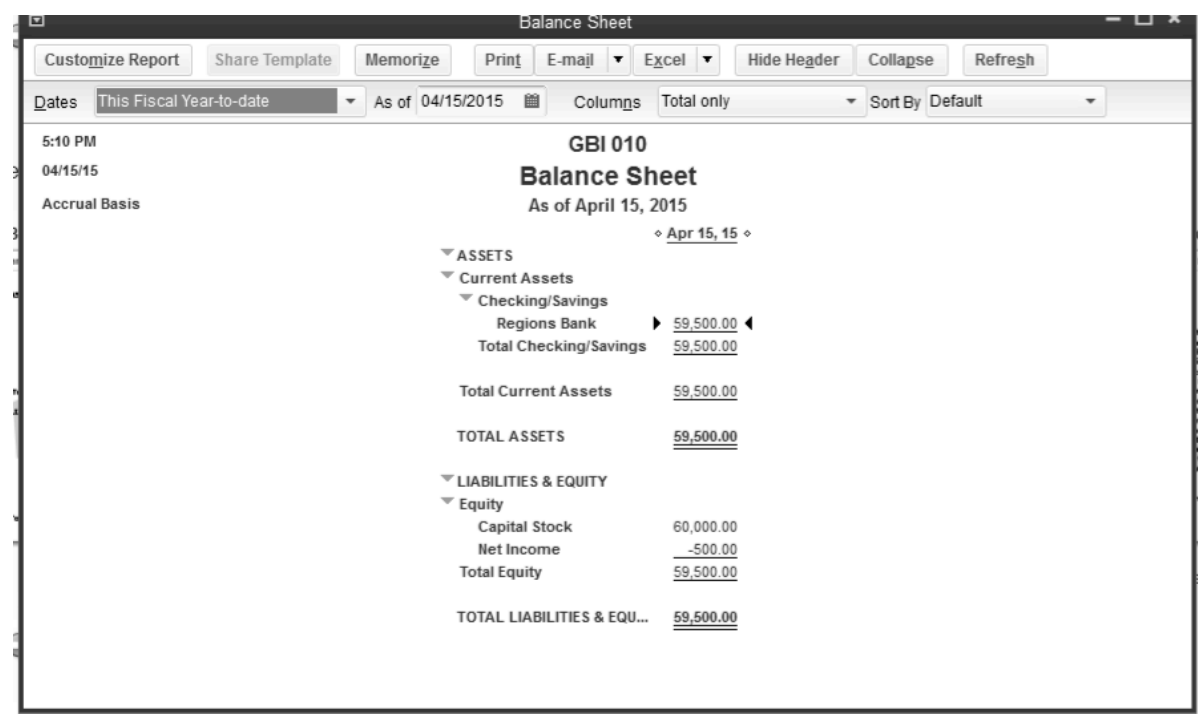

Figure 5. Balance Sheet after G/L Entries 


\section{Process Activities for Purchase Cycle}

QuickBooks does not support purchase requisitions. The remaining cycle in both SAP and QuickBooks are similar. As can be seen from Table 1 and Table 2, the four activities in both the system are - create purchase order, receive items (called create goods receipt in SAP), receive bill (invoice in SAP), and pay vendor. After creating the purchase order (PO), all other process activities are linked to the PO. Receiving items in QuickBooks is a two screen exercise; both the screens are populated after the user selects the vendor and then the PO.

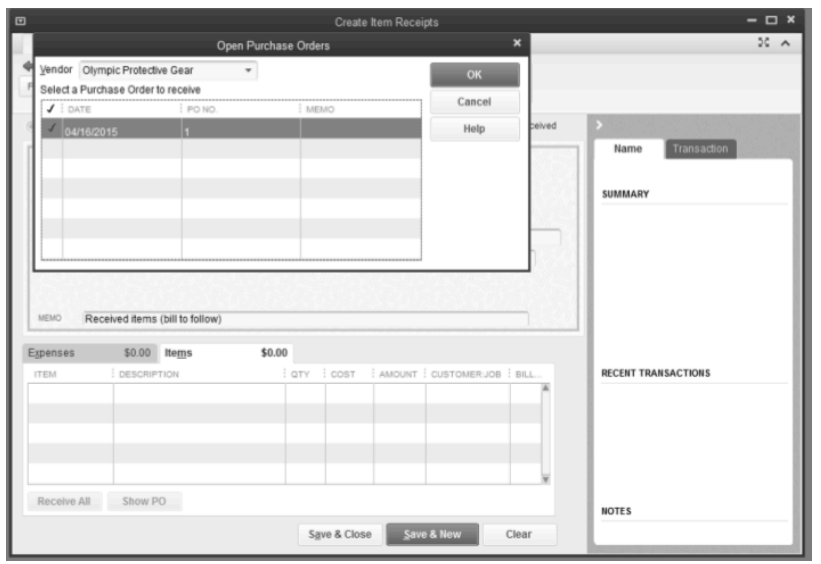

Figure 6. Receive Items-1

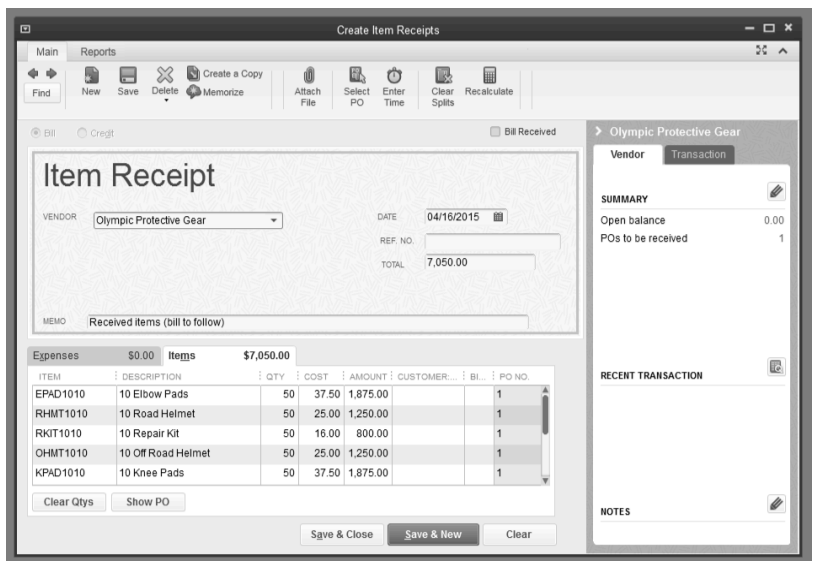

Figure 7. Receive Items-2

The tutorial requires the student to print the Inventory Valuation summary report as shown in Figure 8 below. This report shows how the receipt of items changes the inventory status. 


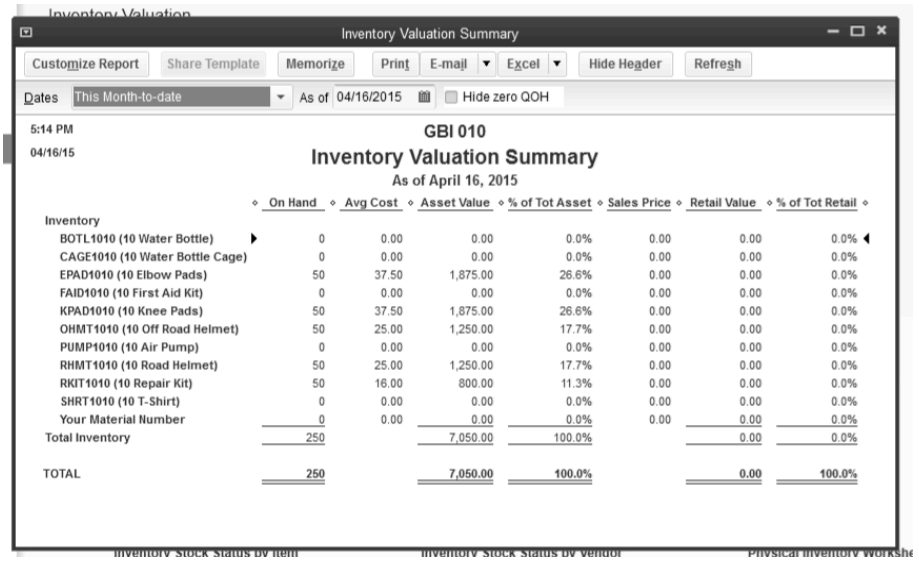

Figure 8. Inventory Valuation

After receiving items, the student is required to enter and pay the bill, followed by printing an updated balance sheet reflecting the changes in inventory and bank account noted in Figure 9 below.

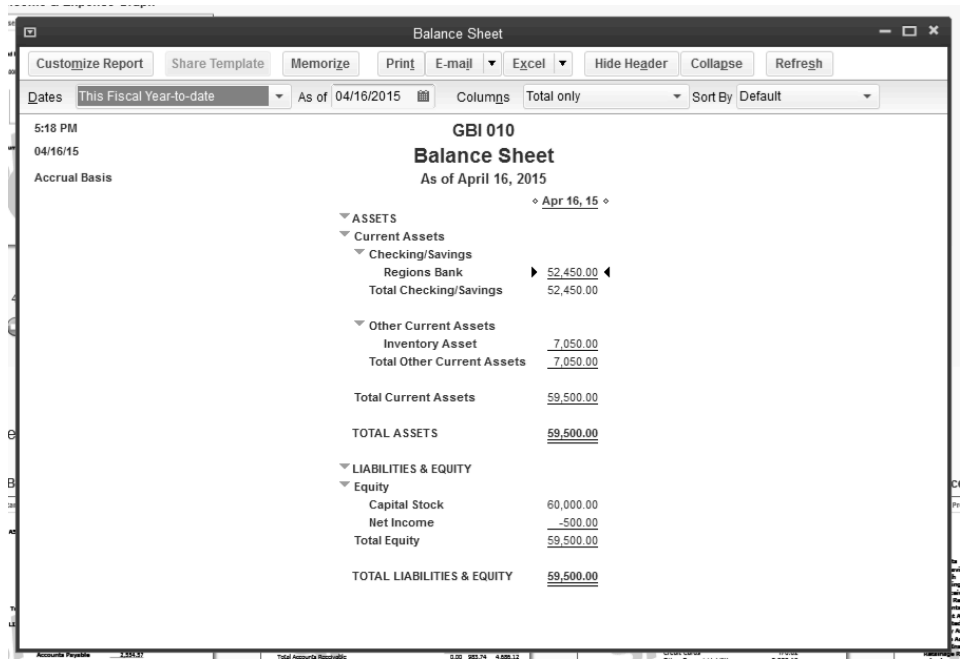

Figure 9. Balance Sheet

The student is able to reinforce some of the fundamental accounting concepts such as Current Assets and Invemtory Assets through the balance sheet.

\section{Process Activities for Fulfillment (Sales) Cycle.}

QuickBooks does not support Sales Quotation, and Create Outbound Delivery and Ship Materials are combined in one activity- Create Sales Order Fulfillment. This combined activity allows the business to print pick list and packing list as shown below. The system also allows for partial fulfillment. The Sales Order Fulfillment Worksheet is shown below in Figure 10. 


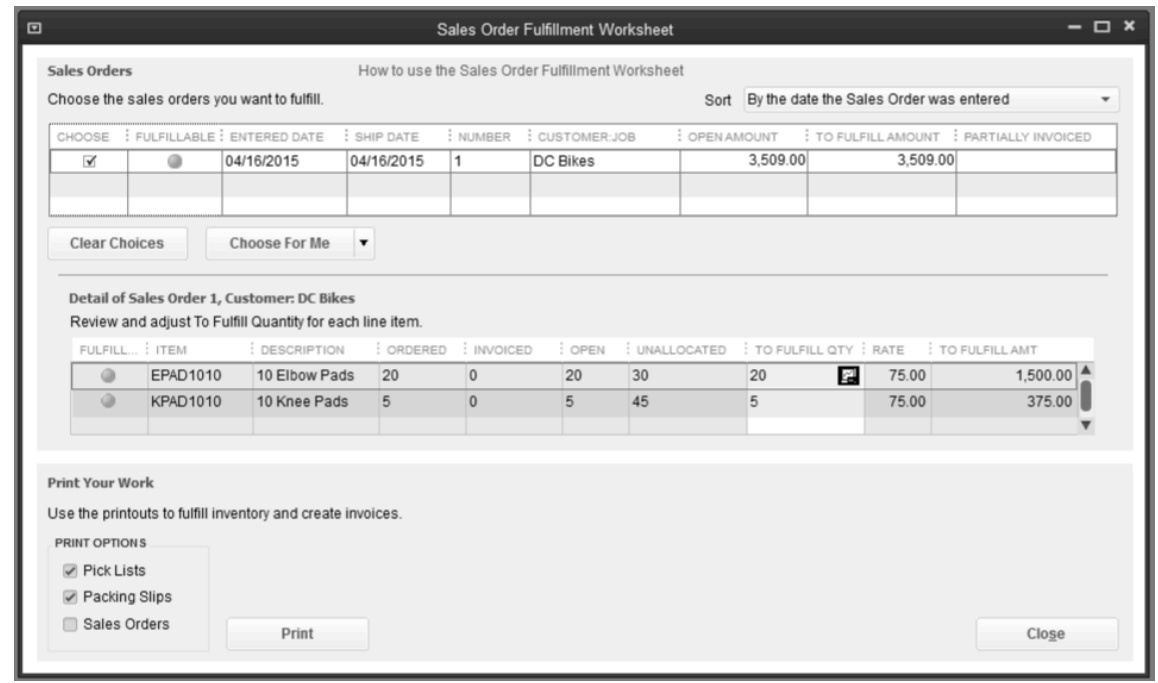

Figure 10. Sales Order Fulfillment

After finishing the activity of fulfilling the sales order, the student is required to create and invoice and print the Inventory Valuation summary again. This report shows how inventory levels decrease after the sales order has been fulfilled. Then the student must receive payment on the invoice and print two statements, the Income by Customer report and the P\&L statement, which are shown in Figures 11-12.

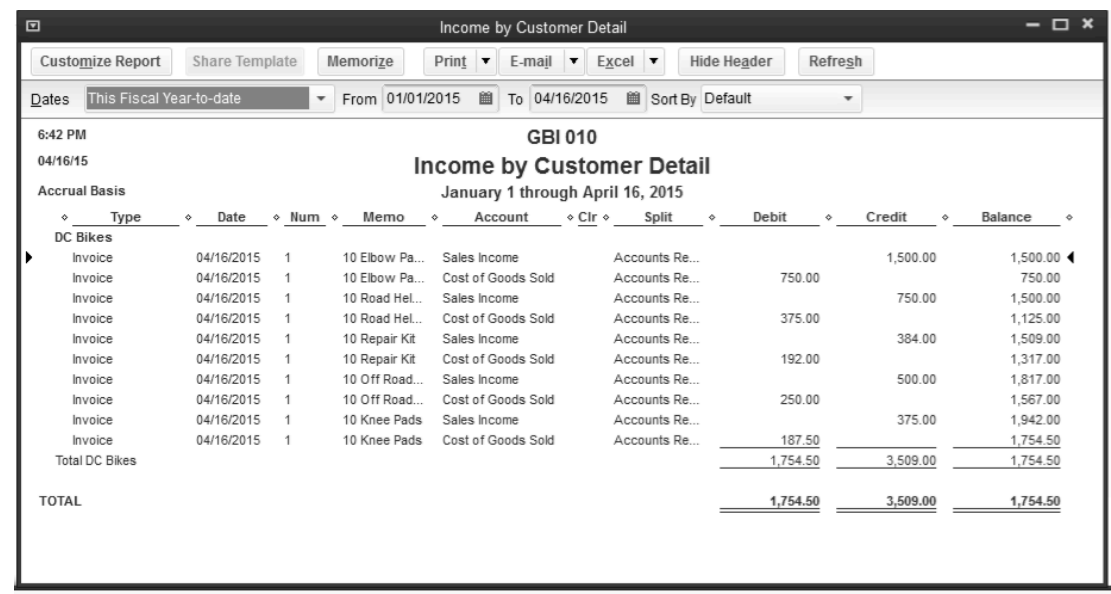

Figure 11. Income by Customer 


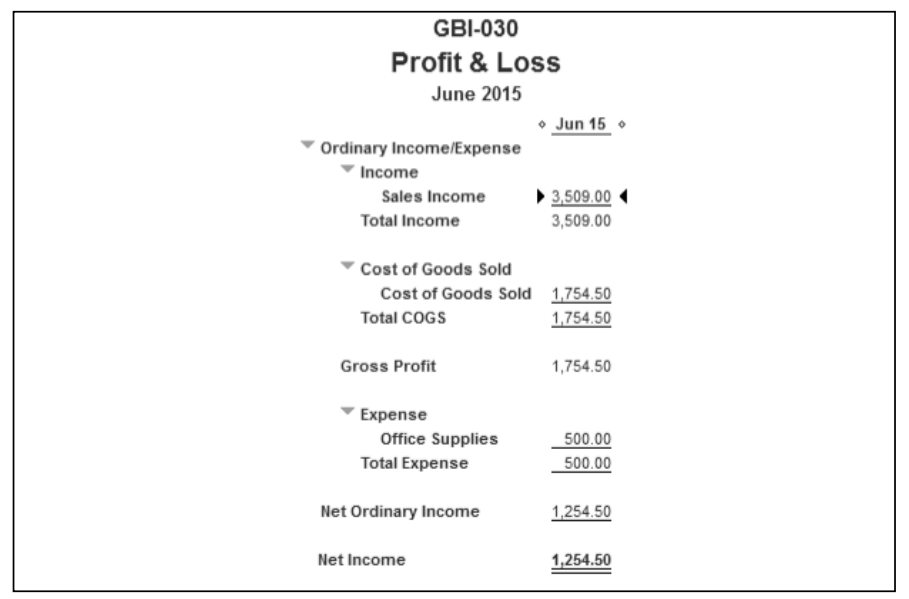

Figure 12. Profit \& Loss Statements

\section{RESEARCH METHODOLOGY}

Our research centered upon the following research question: Did the QuickBooks tutorial help the students understand the concepts of configuration and process activities? The tutorial on QuickBooks was a required classroom assignment for all students enrolled in the SAP configuration course. They were required to complete the assignment after they had finished configuring the company on SAP. We developed a small survey that was completed by all students enrolled in the class. The survey instrument is shown below:

Table 3. Survey

\begin{tabular}{|c|c|c|c|}
\hline \multirow[t]{2}{*}{ The QuickBooks Module Helped Me } & \multicolumn{3}{|c|}{ 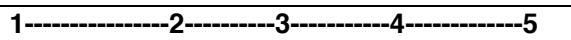 } \\
\hline & $\begin{array}{l}\text { Strongly Agree } \\
\text { Agree }\end{array}$ & Neutral & $\begin{array}{l}\text { Strongly } \\
\text { Disagree }\end{array}$ \\
\hline $\begin{array}{l}\text { Better understand concepts such as P\&L, Balance Sheets, and } \\
\text { Inventory Management. }\end{array}$ & \multicolumn{3}{|c|}{ 5-point Likert Scale as above } \\
\hline $\begin{array}{l}\text { Better understand the GBI business case such as what I was buying } \\
\text { and selling }\end{array}$ & \multicolumn{3}{|c|}{ 5-point Likert Scale as above } \\
\hline Better understand the profit margins in $\mathrm{GBI}$ case & \multicolumn{3}{|c|}{ 5-point Likert Scale as above } \\
\hline Better understand the concept that office supplies can be expensed out & \multicolumn{3}{|c|}{ 5-point Likert Scale as above } \\
\hline Better understand the complexity of SAP and the configuration process & \multicolumn{3}{|c|}{ 5-point Likert Scale as above } \\
\hline Better understand the Sales Cycle & \multicolumn{3}{|c|}{ 5-point Likert Scale as above } \\
\hline Better Understand the Procurement Cycle & \multicolumn{3}{|c|}{ 5-point Likert Scale as above } \\
\hline The QuickBooks Module should be a part of CIS 329. & Yes & No & \\
\hline $\begin{array}{l}\text { The QuickBooks should be taught at the beginning or at the end of the } \\
\text { configuration course. (Circle One) }\end{array}$ & Beginning & End & \\
\hline
\end{tabular}

\section{RESULTS}

All twenty students enrolled in the class completed the tutorial after they had finished the SAP configuration. A total of twenty responses were received. The results are shown in the table below:

Table 4. Results

\begin{tabular}{|c|c|c|}
\hline Survey Questions & Mean & SD \\
\hline \multicolumn{3}{|l|}{ The QuickBooks module helped me } \\
\hline Better understand concepts such as P\&L, Balance Sheets, and Inventory Management. & 1.25 & 0.44 \\
\hline Better understand the GBI business case such as what I was buying and selling & 1.3 & 0.47 \\
\hline Better understand the profit margins in GBI case & 1.7 & 0.73 \\
\hline Better understand the concept that office supplies can be expensed out & 3 & 0.86 \\
\hline Better understand the complexity of SAP and the configuration process & 2.2 & 0.62 \\
\hline Better understand the Sales Cycle & 2.3 & 0.80 \\
\hline Better Understand the Procurement Cycle & 2.3 & 0.80 \\
\hline
\end{tabular}




\begin{tabular}{|l|c|c|}
\hline The QuickBooks Module should be a part of CIS 329. & Yes-100\% & Beginning:15 \\
\hline The QuickBooks should be taught at the beginning or at the end of the configuration course. & End:5 \\
\hline
\end{tabular}

The results suggest that the QuickBooks module was effective. All students wanted this module to be a part of the configuration class. $75 \%$ of the students responded that the QuickBooks module should be taught at the beginning of the course and not at the end as was done in our study.

\section{LIMITATIONS}

One of the major issues with using the SAP UA tutorials and exercises in an undergraduate course is the lack of understanding of the underlying ERP, accounting and business process concepts. This understanding can also be improved by using a textbook along with the tutorials. Although the course recommends a text book written by Magal and Word [4] as a reference guide and a conceptual resource, most students rely on the tutorial and the PowerPoint and tutorials developed by the University Alliance.

The learning of the students were measured through their self-perception. The results would be more conclusive if we had used two set of classes (larger sample) and used the treatment (reinforcing concepts using the QuickBooks tutorial) on one of the class and then measured the students' learning.

\section{CONCLUSIONS}

QuickBooks uses simplified language and a clean, attractive user interface and straightforward navigational tools to make accounting more understandable for non-accountants [5]. Although many of the large ERP vendors have offered products for the small and mid-sized businesses they have not been able to dislodge QuickBooks. One reason could be that it's difficult to take complex software and dumb it down [6]. Our university was struggling to introduce QuickBooks into the curriculum but could not find an easy and effective way. This experiment killed two birds; we were able to reinforce the concepts involved in configuring complex software such as SAP and also expose students to the simplicity of QuickBooks.

\section{REFERENCES}

1. Antonucci, Y. L., Corbitt, G., Stewart, G., \& Harris, A. L. (2004). Enterprise systems education: Where are we? Where are we going? Journal of Information Systems Education, 15(3), 227-234.

2. Kiwi startup Xero pries accountants away from Intuit's QuickBooks | Xconomy. (2014, June). Available: http://www.xconomy.com/san-francisco/2014/06/30/kiwi-startup-xero-pries-accountants-away-from-intuitsquickbooks

3. Magal, S., \& Word, J. (2012). Integrated business processes with ERP systems. Hoboken, NJ: Wiley.

4. New curricula for UAP members: SAP ERP configuration using GBI. (n.d.). Available: http://scn.sap.com/community/uac/blog/2013/01/10/new-curricula-for-uap-members-sap-erp-configurationusing-gbi.

5. QuickBooks Enterprise Solutions. (n.d.). Available: http://www.pcmag.com/article2/0,2817,2421706,00.asp

6. QuickBooks Enterprise: The forgotten mid-market ERP player $\mid$ ZDNet. (n.d.). Available: http://www.zdnet.com/article/quickbooks-enterprise-the-forgotten-mid-market-erp-player

7. SAP AG University Alliance. (2013) Introduction to SAP ERP using Global Bike Inc. 2.11. Available: https://cw.sdn.sap.com/cw/docs/DOC-153068

8. Weidner, S. (2012). Global Bike Inc. 2.11, SAP University Alliances. 